\title{
Early-Life Experience, Epigenetics, and the Developing Brain
}

\author{
Marija Kundakovic ${ }^{1}$ and Frances A Champagne ${ }^{*, 1}$ \\ ${ }^{1}$ Department of Psychology, Columbia University, New York, NY, USA
}

\begin{abstract}
Development is a dynamic process that involves interplay between genes and the environment. In mammals, the quality of the postnatal environment is shaped by parent-offspring interactions that promote growth and survival and can lead to divergent developmental trajectories with implications for later-life neurobiological and behavioral characteristics. Emerging evidence suggests that epigenetic factors (ie, DNA methylation, posttranslational histone modifications, and small noncoding RNAs) may have a critical role in these parental care effects. Although this evidence is drawn primarily from rodent studies, there is increasing support for these effects in humans. Through these molecular mechanisms, variation in risk of psychopathology may emerge, particularly as a consequence of early-life neglect and abuse. Here we will highlight evidence of dynamic epigenetic changes in the developing brain in response to variation in the quality of postnatal parent-offspring interactions. The recruitment of epigenetic pathways for the biological embedding of early-life experience may also have transgenerational consequences and we will describe and contrast two routes through which this transmission can occur: experience dependent vs germline inheritance. Finally, we will speculate regarding the future directions of epigenetic research and how it can help us gain a better understanding of the developmental origins of psychiatric dysfunction.
\end{abstract}

Neuropsychopharmacology Reviews (2015) 40, I4I-153; doi:10.1038/npp.20I4.I40; published online 30 July 2014

\section{INTRODUCTION}

Development typically occurs within a social context comprising parents, siblings, and other caregivers or group members. This context provides for the developmental needs of offspring, such as feeding, sensory stimulation, and emotional warmth, but may also serve as a critical cue to the type of environment in which immediate and later development will take place. For example, although basic needs may be met through the efforts of a single caregiver, the absence of other individuals (eg, friends and relatives) may indicate a lack of social support or financial constraint, which may typify the environment to be experienced over the lifespan. Given the potential value of these environmental signals in predicting both the current and future socioeconomic context, it is perhaps not surprising that the quality of the early-life environment can have a sustained impact on our biology, leading to divergent developmental trajectories. In particular, the quality of parent-offspring interactions can shape the developing brain with long-term implications for brain function and

${ }^{*}$ Correspondence: Dr FA Champagne, Department of Psychology, Columbia University, 406 Schermerhorn Hall, 1190 Amsterdam Avenue, New York, NY 10027, USA, Tel: +1 212854 2589, Fax: +1 2128543609 , E-mail: fac2105@columbia.edu

Received 14 April 2014; revised 3 June 2014; accepted 5 June 2014; accepted article preview online 11 June 2014 behavior. A critical question raised by decades of research into the developmental effects of parenting is regarding mechanism: how does the experience of variation in parental care lead to lifelong changes in neurobiology and behavior?

The search for mechanism(s) underlying the impact of parents on offspring has progressed rapidly in the past decade in light of modern advances in molecular biology and brain imaging that point toward pathways, which may be common to many early-life experiences (ie, exposure to toxins, nutritional variation, and stress). In particular, it is evident that the quality of parent-offspring interactions induce epigenetic changes in the developing brain that account for variation in response to stress, cognition, sociality, and reproductive behavior. Epigenetics is an evolving field of study that focuses not on the sequence of DNA within our genomes but rather on regulation of the 'activity' of genes. These epigenetic mechanisms may help us to better understand the biological impact of a broad range of environmental experiences, which include the quality of parental care. Moreover, it is clear that the impact of early-life experiences may influence subsequent generations of offspring. In this review, we will highlight evidence for the neurobiological and behavioral impact of parentoffspring interactions occurring during the postnatal period, the epigenetic mechanisms through which these effects may be achieved, and explore the transgenerational consequences of parental care and early-life adversity. 


\section{ENDURING IMPACT OF PARENTAL CARE}

The context of development can vary significantly between individuals. Although the sources of this variation may involve broad ecological factors, such as climate, population density, and socioeconomic status, from the perspective of the developing individual, these contextual factors are experienced indirectly through the influence of the environment on parent-offspring interactions. The dependence of offspring on these interactions may extend beyond survival. Socioemotional systems that govern self-regulation and stress reactivity may develop through an experienceexpectant process that depends on species-specific forms of early-life social interactions. This developmental process is demonstrated in studies of the impact of variation in or disruption to the quality of parent-offspring interactions in humans, primates, and rodents.

\section{Parental Care, Neglect, and Abuse in Humans}

Research on the developmental impact of human parental behaviors has focused on the quality of the attachment, sensitivity to infant cues, parental bonding, and disturbances to the parent-child relationship through parental absence (ie, institutional rearing), neglect, and abusive caregiving. Variations in the attachment relationship (typically examined between mother and infant) are associated with either resilience to psychological distress (eg, secure attachment) or increased incidence of psychopathology (eg, disorganized attachment) (Sroufe, 2005). Disorganized attachment is predictive of increased rates of personality disorder, dissociation, self-harm, and increases in salivary cortisol during exposure to stressors, suggesting heightened reactivity of the hypothalamic-pituitary-adrenal (HPA) response to stress (Bernard and Dozier, 2010; Carlson, 1998; Carlson et al, 2009; van Ijzendoorn et al, 1999). Among infants whose mothers are characterized as exhibiting a low $v s$ high frequency of sensitive/non-intrusive caregiving, there are increased fear responses and reduced frontal electroencephalographic asymmetry (a predictor of increased HPA reactivity; see Figure 1a) at 9 months of age (Hane and Fox, 2006) than persist at 2-3 years of age (see Figure 1b; Hane et al, 2010). Parental bonding, which includes indices of the degree of care and overprotectiveness, is a significant predictor of later-life depression (associated with low care and high overprotectiveness; Parker, 1990) and may induce changes in gray matter volume in the prefrontal cortex and hippocampus, as well as altered dopaminergic and cortisol response to stress (Engert et al, 2010; Narita et al, 2010, 2012; Pruessner et al, 2004). Thus, even variation within the normal range of parental behavior can have a significant impact on neurobehavioral outcomes.

Adverse childhood experiences that include childhood neglect and abuse have been found to predict reduced cognitive performance, impaired social development, and an increase in personality disorders (Johnson et al, 1999; Trickett and McBride-Chang, 1995). These outcomes may
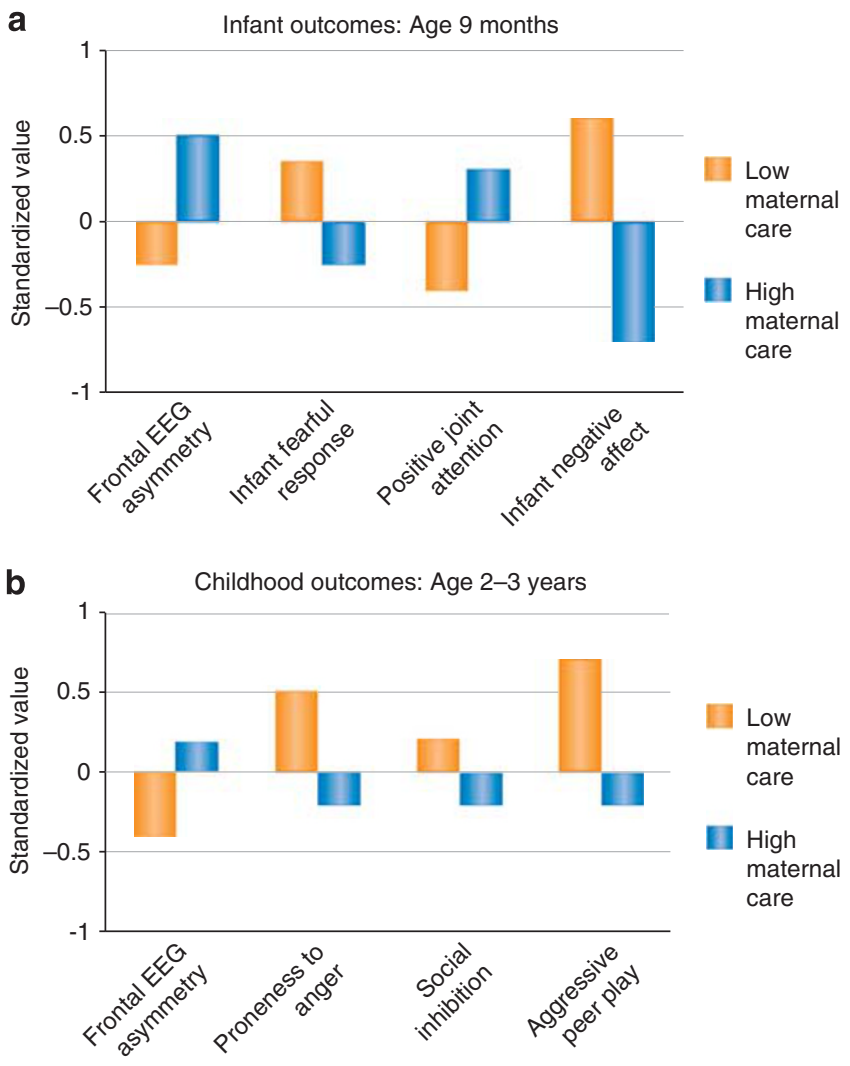

Figure 1. Impact of low vs high-quality maternal care in humans on (a) infant and (b) childhood outcomes. Adapted from Hane and Fox (2006) and Hane et al (2010).

be driven in part by the HPA dysregulation that characterizes individuals that have experienced neglect and/or abuse (Carpenter et al, 2011; Heim et al, 2010). Within brain imaging studies, childhood emotional maltreatment is associated with a smaller medial prefrontal cortex (van Harmelen et al, 2010), and alterations in volume and activation in response to threat cues have been found in several brain regions including the amygdala and hippocampus (De Bellis, 2005; Maheu et al, 2010). The severe neglect experienced by institutionalized infants (eg, Romanian orphans) results in developmental delays, impaired executive functioning, increased autistic-like behaviors, and elevated salivary cortisol levels (Gunnar et al, 2001; Hostinar et al, 2012; O'Connor et al, 2000; Rutter and O'Connor, 2004). Similar to non-institutionalized infants that have a history of neglect/abuse, orphanage-reared children have heightened amygdala activity (Tottenham et al, 2011). Heightened brain activity, particularly in the amygdala and hippocampus, in response to threatening cues, emerges as a common neurobiological marker of disruption to the parent-infant relationship, resulting in impaired social interactions (Maheu et al, 2010).

Although the neurobiological impact of low parental care, abuse, and neglect are often conceptualized as separate forms of early-life experience, there is significant interrelation 
between these forms of adversity. Disorganized attachment is observed in $48-80 \%$ of maltreated/abused infants (Johnson et al, 1999). Institutionalized rearing is associated with disorganized attachment relationships and interventions focused at creating more stability in caretaker-infant interactions can enhance attachment and improve longterm outcomes (Smyke et al, 2002). Moreover, the quality of the attachment relationship may be a mediator of the longterm effects of early-life social deprivation on symptoms of psychopathology (McGoron et al, 2012). Attachment security is predicted by the quality of parental care, including sensitivity and synchrony of interactions (De Wolff and van Ijzendoorn, 1997). Thus, these early-life experiences may be collectively part of a developmental cascade that contributes to vulnerability to neurobiological and behavioral disruption.

\section{Impact of Parental Behavior in Primates}

Studies in non-human primates suggest that the degree of contact between mother and infant and indices of rejection/ abuse can have lasting behavioral and neurobiological consequences. Maternal deprivation, achieved through nursery rearing, has a profound impact on the development of rhesus macaques, which leads to disruptions in social behavior, hyperactivity, and sensitivity to stressors (Harlow et al, 1965; Suomi et al, 1971). Among mother-reared vs peer-reared macaques (Suomi, 1991), where infants have social contact with peers but not with the mother, peerreared infants exhibit long-term disruptions to behavior, neuroendocrine response to stress, and brain development (Dettmer et al, 2012; Spinelli et al, 2009, 2010). The quality and quantity of mother-infant interactions in primates can also be altered by varying the duration of time needed to forage each day (Coplan et al, 2006). Variable foraging demand results in reduced sensitivity of mothers to infant cues, resulting in elevated levels of anxiety-like behavior, reduced social behavior, and disruptions to hippocampal development and function in offspring (Coplan et al, 2005; Gorman et al, 2002; Jackowski et al, 2011). In colonies of macaques, maternal abuse (ie, dragging and stepping-on infants) occurs at a frequency of $2-10 \%$ and is associated with a delay in the onset of social play and heightened aggression in novel environments (McCormack et al, 2006). Abusive mothers also engage in high levels of maternal rejection, which is predictive of HPA disruption, brain morphology, and serotonergic function in offspring (Howell et al, 2013; Koch et al, 2014; Maestripieri et al, 2006; Sanchez et al, 2010). Non-human primates have also been observed to vary in their frequency of mother-infant contact (ie, an over-protective parenting style), and high levels of contact predicts decreased exploration of a novel environment (Fairbanks and McGuire, 1988). In marmosets, rearing occurs in a family context and higher rates of rejection of offspring by mothers, fathers, or siblings during the first 2 months of life results in elevated stress-induced cortisol responses (Birnie et al, 2013). Thus, the social context of rearing may induce a lasting impact on stress reactivity.

\section{Developmental Impact of Maternal Behavior in Laboratory Rodents}

The study of parental care in laboratory rodents includes a variety of experimental approaches, including exposure to early-life maternal separation or deprivation, induced disruption or enhancement of mother-infant interactions, and natural variations in maternal care. In rodents, prolonged postnatal maternal separation induces elevations in glucocorticoid hormone levels (Stanton et al, 1988), a heightened response to stress, and impaired cognitive functioning (Andersen et al, 1999; Lehmann et al, 1999). Complete maternal deprivation, comparable to the experience of institutionalized children or nursery/peer-reared monkeys, can be implemented in rats by rearing pups in the absence of maternal contact (artificial rearing). Pups reared under these conditions exhibit impaired social learning (Levy et al, 2003), reduced attention (Lovic and Fleming, 2004), and increased impulsivity (Lovic et al, 2011). Within the brain, maternally deprived pups have reductions in neurotrophic factors, which may result in impaired neural development and reduced plasticity (Chatterjee et al, 2007). Reduction in neurotropic factors in the prefrontal cortex is also observed in pups that have experienced abusive caregiving in infancy (Roth et al, 2009). Similar to the case of attachment in humans, fragmentation of mother-infant interactions may be a common pathway in many of these models of adversity and serve a mediating role in predicting long-term outcomes in offspring (Baram et al, 2012). This unpredictability of care can be achieved through removal of bedding material from the home-cage (Rice et al, 2008), and lead to reduced nurturing and increased abusive maternal interactions (eg, stepping on pups, aggressive grooming, and transporting of pups by a limb) with offspring, as well as increased basal corticosterone and impaired learning/ memory, likely mediated through forebrain corticotropin releasing-factor receptor 1 signaling (Rice et al, 2008; Roth et al, 2009; Wang et al, 2011).

The study of natural variations in maternal care in rodents has provided a compelling model for studying the impact of mother-infant interactions within the normal range. Observations of Long-Evans rats during the postpartum period indicate that licking/grooming (LG) of pups, one of the primary forms of tactile stimulation during postnatal development, varies significantly between lactating dams (Champagne et al, 2003a). In adulthood, offspring that experienced low compared with high levels of LG have heightened stress-induced glucocorticoid levels (Liu et al, 1997), reduced hippocampal plasticity (Bagot et al, 2009), and impaired learning/memory (Liu et al, 2000). These functional outcomes are attributable to reduced glucocorticoid receptor (GR) protein and mRNA in the hippocampus of offspring reared by low-LG dams (Francis et al, 1999; Liu et al, 1997). Hippocampal GR has a critical negative-feedback role 
within the HPA response to stress (Sapolsky et al, 1985) and reduced levels of GR may account for the heightened stress responsivity observed in low-LG offspring (see Figure 2). Similar to other rodent models of early-life adversity, neurotrophic factors are reduced within the brain of offspring reared by a low-LG dam (Liu et al, 2000). These maternal phenotypes are also transmitted to female offspring, such that the experience of low-LG predicts low-LG in offspring (Champagne et al, 2003a). In contrast, low-LG female offspring exhibit increased sexual behavior, suggesting that the quantity of maternal care experienced in infancy leads to shifts in reproductive strategy of offspring (Cameron et al, 2005, 2008). These maternal/reproductive phenotypes are associated with brain region-specific effects on oxytocin and estrogen receptor (ER) levels (Cameron et al, 2008; Champagne et al, 2001, 2003b). Importantly, cross-fostering studies confirm that these neurobiological effects are a consequence of variation in postnatal maternal care (Champagne et al, 2006b; Francis et al, 1999)

The quality of maternal care during the postnatal period can be modulated by a variety of environmental manipulations. In rats, maternal LG can be increased by housing post-weaning females in conditions of increased social and physical enrichment (eg, group housing with toys and a complex housing design) before mating (Champagne and Meaney, 2007). Conversely, LG can be decreased when females experience long periods of social isolation or stress during pregnancy (Champagne and Meaney, 2006a; Champagne et al, 2007). Brief periods of maternal separation (ie, lasting 5-20 $\mathrm{min}$ ) has been demonstrated to increase maternal LG (Lee and Williams, 1974; Liu et al, 1997) and attenuate the stress responsivity of offspring (Ader, 1970). This effect has been attributed to the impact of increased maternal stimulation of offspring on hippocampal

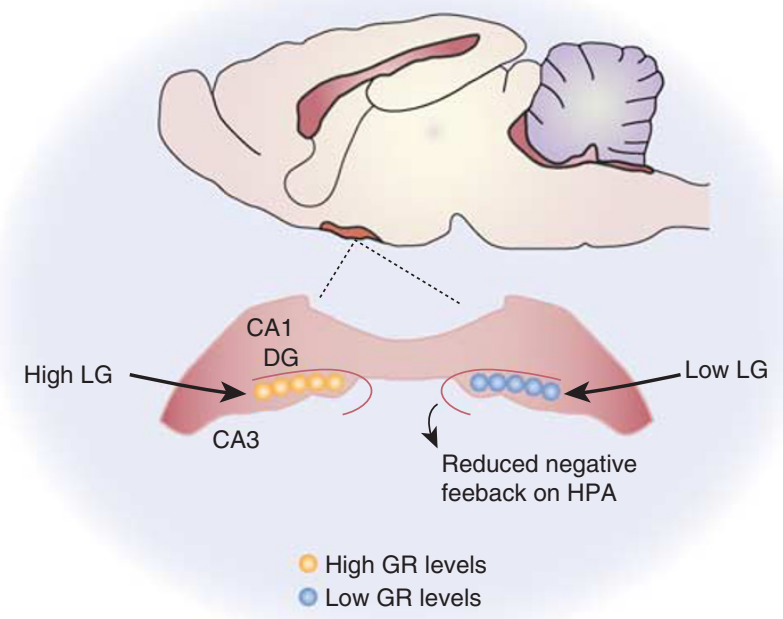

Figure 2. Schematic illustration of the impact of low vs high maternal LG on hippocampal GR levels. Low levels of maternal LG are associated with decreased GR levels resulting in impaired negative-feedback on the HPA response to stress. CA1, cornu ammonis 1; CA3, cornu ammonis 3; DG, dentate gyrus.
GR levels (Meaney et al, 1985). The experience of brief maternal separation during postnatal development has also been demonstrated to enhance hippocampal-dependent memory (Tang, 2001), although the experience of a novel environment during the separation may be a critical variable in predicting these effects (Tang et al, 2006). In mice, adult females can be induced to increase pup-directed behavior when placed in a communal nest, consisting of multiple caregivers and litters (Curley et al, 2009). Offspring reared in a communal nest are more exploratory in a novel environment, display higher levels of social behavior, and have increased hippocampal neurotrophin levels (Branchi et al, 2006a, b, 2013; Curley et al, 2009). In adulthood, communally reared females display higher levels of maternal care toward their own offspring and have elevated levels of hypothalamic oxytocin receptors (Curley et al, 2009). Thus, there are striking parallels between the experience of communal rearing and being reared by a high-LG mother.

\section{Studies of Paternal Influences on Offspring Development in Rodents}

Although laboratory studies of parental influence have been predominated by investigations of maternal care, it is important to note that fathers can similarly shape the development of offspring. In socially monogamous and biparental species, deprivation of paternal care can result in reduced social recognition (Cao et al, 2014), altered development of play behavior (Wang et al, 2012), impaired pair-bonding ( $\mathrm{Yu}$ et al, 2012), and increased anxiety-like behavior (Jia et al, 2009). These behavioral impairments are associated with paternal deprivation-induced neurobiological changes, including sex-specific effects on dopamine receptor gene expression in the nucleus accumbens (Yu et al, 2012), reductions in oxytocin receptor and ER alpha $(\mathrm{ER} \alpha)$ levels (Cao et al, 2014), altered development of neuroendocrine pathways involved in the response to stress (Seidel et al, 2011), and reduced neuronal complexity (Braun et al, 2013; Pinkernelle et al, 2009). In the biparental California mouse, paternal behavior has been shown to alter the development of neural systems involved in aggression, with implications for variation in paternal behavior in male offspring (Frazier et al, 2006; Gleason and Marler, 2013). Manipulations of the quantity of paternal care in California mice, through use of a high foraging demand, leads to impairment in offspring learning and memory, increased indices of anxiety-like behavior, and altered synaptic development (Bredy et al, 2007). Thus, in species where fathers contribute to offspring care, paternal deprivation can result in neurobiological and behavioral impairments in offspring.

\section{EPIGENETIC PATHWAYS IN THE DEVELOPING BRAIN}

A critical question is regarding the mechanism(s) through which variation in parent-offspring interactions leads to long-term shifts in brain function and behavior. The search 
for mechanism has pointed increasingly at the molecular pathways regulating gene activity, including DNA methylation, posttranslational histone modifications, and non-coding RNAs, which have a critical role in brain development.

\section{DNA Methylation}

The addition of a methyl group to cytosines within DNA, particularly within $\mathrm{CpG}$ dinucleotides, is typically considered a stable and enduring epigenetic modification (Razin, 1998), although, it should be noted that there is evidence for dynamic changes in this epigenetic mark in response to acute environmental exposures (Barres et al, 2012) and memory formation (Day and Sweatt, 2010) in the adult brain. When cytosines become methylated there is generally less accessibility to the DNA and consequently DNA methylation is thought to be associated with gene silencing (Razin, 1998). Methylated DNA can recruit methyl CpGbinding proteins (eg, $\mathrm{MeCP} 2$ ), which cluster around the DNA and attract histone-modifying enzymes that induce repressive chromatin structure in the surrounding gene region (Fan and Hutnick, 2005). During cellular differentiation, the reliable transmission of DNA methylation patterns from mother to daughter cells contributes to the emergence of cellular diversity and maintenance of cellular phenotypes among cells containing identical DNA sequences. Thus, the epigenetic signature of a cell determines cellular phenotypes, which can be inherited through mitosis (Taylor and Jones, 1985). The rapid proliferation and differentiation of cells that occurs during prenatal and postnatal development require both de novo and maintenance DNA methylation. Disruption to these processes, through targeted deletion of genes encoding DNA methyltransferases (Dnmt1 or Dnmt3a/3b), lead to genome-wide hypomethylation, impaired growth, and embryonic or postnatal lethality (Jackson-Grusby et al, 2001; Okano et al, 1999). In humans, polymorphisms in DNMT genes have been identified (El-Maarri et al, 2009) and these genotypes may be important to consider in understanding individual differences in epigenetic dysregulation and neurodevelopmental outcomes.

\section{Posttranslational Histone Modifications}

The expression of genes requires that DNA become accessible to transcription factors and to the general transcription machinery that includes RNA polymerase. One strategy to achieve this outcome is to modify the histone proteins in chromatin so as to loosen the physical attraction/interaction between DNA and the histone amino-acid 'tails'. The addition or removal of chemical groups from histone tails can lead to dynamic changes in transcriptional activity, dependent on the type of group and the location of addition/removal (Peterson and Laniel, 2004). For example, tri-methylation at lysine 4 in the histone $\mathrm{H} 3$ tail (H3K4) is associated with increased gene expression, whereas tri-methylation at lysine 9 in histone H3 (H3K9) corresponds with decreased gene expression (Barski et al, 2007;
Koch et al, 2007). There are many chemical groups, which can be added or removed from the histone tails and, collectively, these posttranslational modifications generate a complex strategy for dynamic regulation of gene expression (Jenuwein and Allis, 2001). Disruption to the enzymatic machinery that facilitates these epigenetic processes has profound effects on development. For example, mutation within JARID1C, which encodes for a histone demethylase, is associated with neurodevelopmental disorder, including autism (Adegbola et al, 2008) and mental retardation (Tahiliani et al, 2007).

\section{Non-Coding RNAs}

Although the majority of the genome does not encode for a protein product, this is not to be interpreted to mean that the majority of the genome has no function. This notion is becoming increasingly clear in the case of small non-coding RNA molecules (eg, microRNAs (miRNAs) and piRNAs). miRNAs can cause posttranscriptional gene silencing by base pairing with target messenger RNAs (mRNAs) preventing translation, cleaving the mRNA, or promoting mRNA degradation (Sato et al, 2011). These RNAs, through their ability to target multiple genes, may serve as critical epigenetic regulators. Moreover, changes in the expression of specific miRNAs is associated with the transition from maternal to zygotic control of transcription, cell fate determination, and developmental patterning in the developing organism (Pauli et al, 2011), and mutations that inhibit the production of Dicer, an enzyme that facilitates the production of mature miRNA, can disrupt neurodevelopment (Bernstein et al, 2003; Davis et al, 2008).

\section{EPIGENETIC PROGRAMMING VIA VARIATION IN MATERNAL CARE}

Integrating evidence for the neurodevelopmental impact of parent-offspring interactions with advances in our understanding of the molecular basis of gene regulation (for summary, see Table 1) has been challenging, but may offer critical insights into the biological embedding of early-life experience. One of the groundbreaking studies linking quality of the postnatal environment to epigenetic variation explores the link between the experience of low- $v$ s high-LG in rats and DNA methylation within the promoter region of the GR gene (Nr3c1) (Weaver et al, 2004). Elevated Nr3c1 DNA methylation is observed in hippocampal tissue from adult male offspring of low-LG compared with high-LG mothers. Consistent with the findings of cross-fostering studies, these maternal care-associated effects are not present prenatally or at birth. Rather, increased DNA methylation of $\mathrm{Nr} 3 \mathrm{cl}$ emerges during the first postnatal week and is stably maintained in adulthood. Histone acetylation and binding of transcription factors to the $\mathrm{Nr} 3 \mathrm{cl}$ promoter region is also reduced among the offspring of low-LG dams (see Figure 3), consistent with the hypothesis that increased DNA methylation in this genomic region leads to transcriptional silencing 
TABLE 1 Summary of Epigenetic Effects of Parent-Offspring Interactions

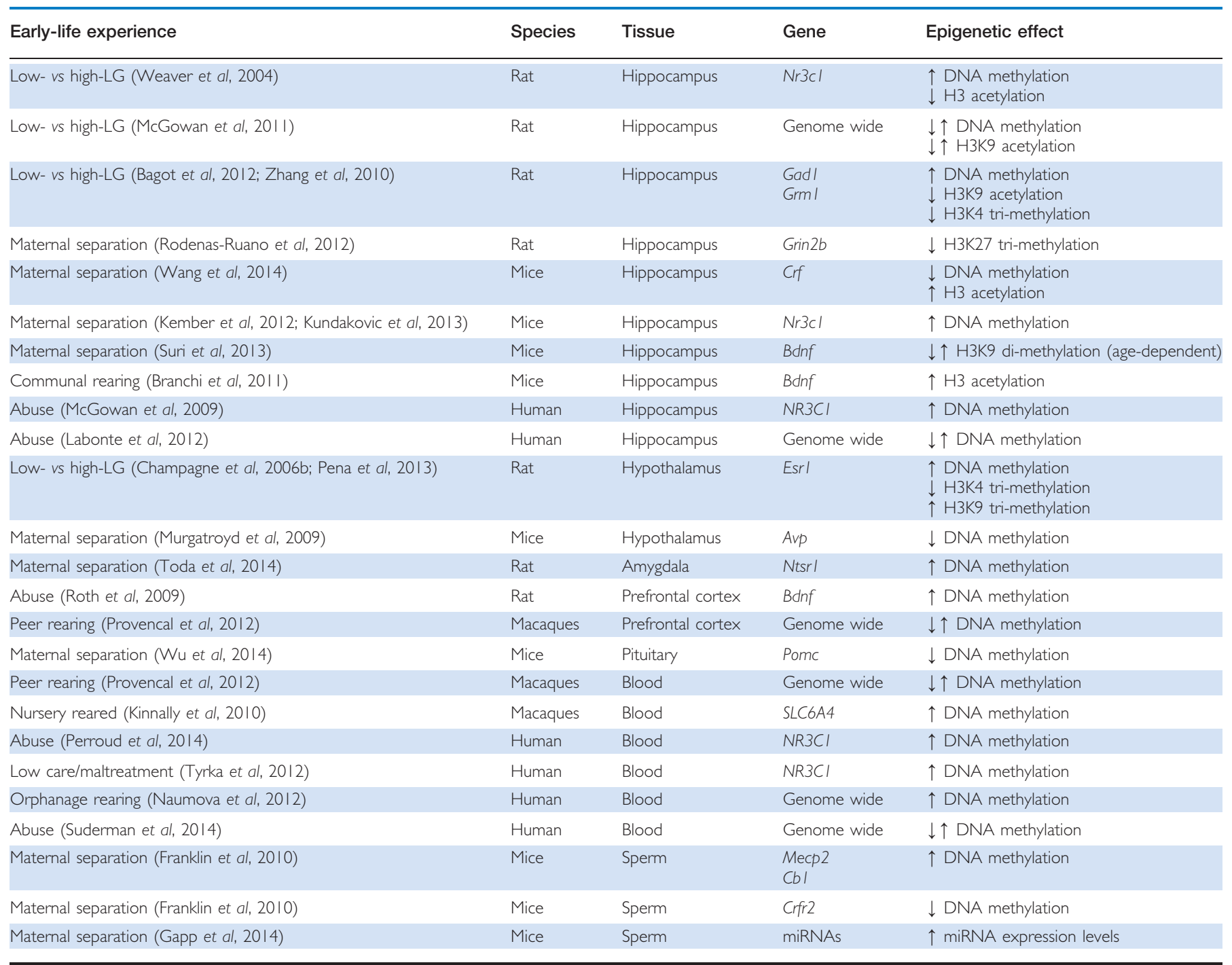

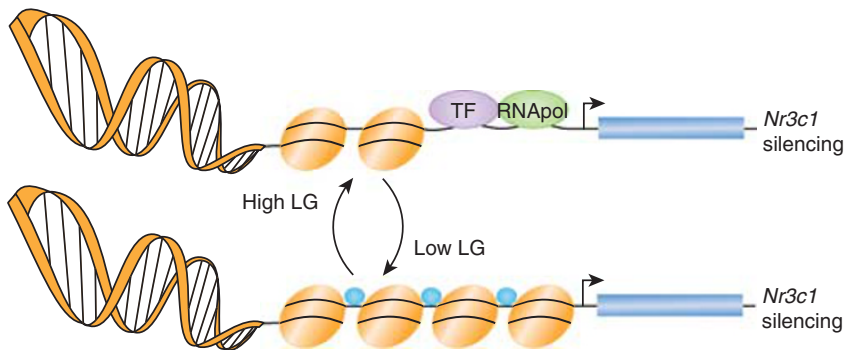

Figure 3. Schematic illustration of the impact of low $v$ s high maternal LG on DNA methylation within the Nr3c1 promoter region. Elevated levels of Nr3c1 DNA methylation are associated with epigenetic silencing of gene expression through inhibition of binding of transcription factors (TF) and RNA polymerase (RNApol).

(Weaver et al, 2004). Although GR represents a key regulator within stress response pathways, it is important to note that variation in maternal LG is associated with changes in the transcription of hundreds of genes (Weaver et al, 2006) and with broad epigenetic alterations in the hippocampus, which include both DNA methylation and histone acetylation (H3K9) (McGowan et al, 2011). Other target genes with epigenetic variation associated with the experience of low- $v s$ high-LG include glutamate decarboxylase (Gad1) and Grm1, which encodes the type I metabotropic glutamate receptor (mGluR1). Low levels of postnatal maternal LG are associated with increased DNA methylation of the regulatory regions of these genes within the hippocampus, as well as decreased levels of H3K9 acetylation and H3K4 tri-methylation (Bagot et al, 2012; Zhang et al, 2010). DNMT1 expression is increased within the hippocampus of low-LG offspring, suggesting a potential mechanism for these broad epigenetic effects (Zhang et al, 2010).

Epigenetic variation associated with the experience of maternal care may also account for the reduced levels of hypothalamic ER observed in female offspring of low-LG compared with high-LG mothers. The experience of low levels of LG during the early postnatal period is associated 
with decreased transcription of Esrl, the gene encoding $\mathrm{ER} \alpha$, within the medial preoptic area of the hypothalamus of adult female offspring (Champagne et al, 2003b). Epigenetic analyses of the Esr1 promoter indicates that low-LG is associated with increased DNA methylation, decreased $\mathrm{H} 3 \mathrm{~K} 4$ tri-methylation, and increased $\mathrm{H} 3 \mathrm{~K} 9$ tri-methylation within this genomic region (Champagne et al, 2006b; Pena et al, 2013). Similar to epigenetic changes within $\mathrm{Nr3c1}$, variation in DNA methylation and histone modifications within Esr 1 emerge during the postnatal period and are not present at birth (Pena et al, 2013). Sex-specific epigenetic programming of Esr1 may account for sexual dimorphism in neuronal circuits and it may be the case that LG experienced during postnatal development contributes to these enduring effects (Kurian et al, 2010). Among communally reared mice that experience enhanced $L G$, there is increased hippocampal $\mathrm{H} 3$ acetylation at several of the brain-derived neurotrophic factor $(B d n f)$ gene promoters, which may lead to transient increases in BDNF protein levels (Branchi et al, 2011).

\section{EPIGENETIC IMPACT OF MATERNAL NEGLECT AND ABUSE}

Profound effects of early-life experience are observed in studies of neglect and abuse and there is growing support for the involvement of epigenetic pathways in the long-term consequences of these forms of adversity (for summary, see Table 1).

\section{Maternal Neglect in Rodents and Primates}

In mice, maternal separation induces increased stress responsivity in offspring, which may be related to the gene expression and epigenetic changes in HPA-associated genes such as vasopressin (Avp), corticotropin-releasing factor $(\mathrm{Crf})$, and $\mathrm{Nr} 3 \mathrm{cl}$. For example, heighten stress sensitivity in offspring may be due to elevated expression of hypothalamic AVP, as maternal separation is associated with decreased DNA methylation and reduced levels of binding of MeCP2 (methyl Cpg-binding protein 2) within the regulatory region of $A v p$ in this brain region (Murgatroyd et al, 2009). Adult mice that have experienced postnatal maternal separation exhibit upregulation of hippocampal $\mathrm{CRF}$ and this increased gene activity is associated with increased $\mathrm{H} 3$ acetylation and decreased DNA methylation of the Crf promoter. Interestingly, the epigenetic changes in Crf associated with maternal separation are reversible in response to post-weaning environmental enrichment (ie, access to increased sensory stimulation and exercise) resulting in an amelioration of maternal separation-induced neurobiological and behavioral impairments (Wang et al, 2014). Increased hippocampal Nr3c1 DNA methylation has also been observed following maternal separation in mice, suggesting that this may be a common epigenetic pathway for many forms of early-life adversity (Kember et al, 2012; Kundakovic et al, 2013).
Beyond stress-related genes within the hippocampus and hypothalamus, early-life disruption to mother-infant interactions may alter the epigenetic state of a variety of gene targets related to neurodevelopmental function in multiple brain regions. Postnatal maternal separation alters H3K27 tri-methylation at the gene encoding $N$-methyl-D-aspartate receptor $(G r i n 2 b)$ in the hippocampus with implications for learning and memory (Rodenas-Ruano et al, 2012). Within the amygdala, maternal separation has been found to increase DNA methylation of the neurotensin receptor (Ntsr1) associated with reduced Ntsr1 mRNA and increased freezing behavior during fear conditioning (Toda et al, 2014). In the pituitary, long-term decreases in cytosine methylation of the proopiomelanocortin $(P o m c)$ gene, a key factor in neuroendocrine stress responses, is observed in maternally separated mice ( $\mathrm{Wu}$ et al, 2014). Within these studies, it may be important to consider the temporal dynamics of environmentally induced epigenetic changes. Studies examining the impact of maternal separation in mice on epigenetic variation within the $B d n f$ gene in hippocampal tissue suggest a biphasic response such that there is decreased H3K9 di-methylation (a repressive chromatin mark) at weaning and in young adults and increased $\mathrm{H} 3 \mathrm{~K} 9$ di-methylation in aging (15-month old) mice (Suri et al, 2013).

In rhesus macaques, global DNA methylation changes that persist into adulthood have been observed in the prefrontal cortex in response to peer rearing. Interestingly, this epigenetic signature of early-life maternal deprivation is also observed in blood samples of peer-reared $v s$ motherreared macaques, suggesting the potential value of peripheral tissues in evaluating the lasting impact of early-life adversity (Provencal et al, 2012). Separation-induced effects on the epigenetic state of SLC6A4, the gene encoding the serotonin transporter (5-HTT), have also been observed (Kinnally et al, 2010). Similar to humans, rhesus macaques possess a SLC6A4 polymorphism, which is associated with variation in risk or resilience to stressors such as childhood maltreatment (Caspi et al, 2003). Rhesus macaques that are reared under conditions of maternal separation and possess the SLC6A4 risk allele have increased SLC6A4 DNA methylation in blood cells (Kinnally et al, 2010). This interaction between genetic and epigenetic variation occurring in response to early-life adversity may further our understanding of the mechanisms involved in gene by environment interactions and will be an important consideration in human studies of early-life adversity.

\section{Epigenetic Effects of Abusive Caregiving in Rodents}

Postnatal maltreatment, induced through removal of bedding material, is associated with reduced BDNF expression in the prefrontal cortex in adulthood (Roth et al, 2009). Among abused offspring, there is increased DNA methylation of $B d n f$ gene promoter regions, which may lead to reduced neuronal plasticity (see Figure 4). Analyses of 


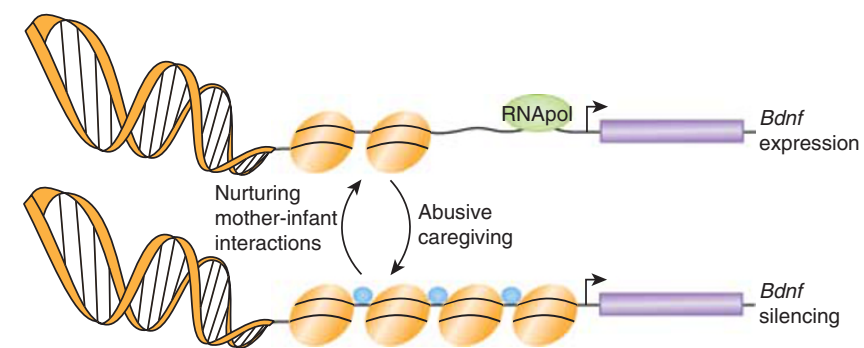

Figure 4. Schematic illustration of the impact of abusive vs nurturing maternal care on DNA methylation within the Bdnf promoter region. Elevated levels of Bdnf DNA methylation induced by the experience of abuse are associated with epigenetic silencing of gene expression through inhibition of RNA polymerase (RNApol) binding to the transcription start site.

epigenetic changes associated with abusive caregiving over developmental time suggest complex interactions between sex and age in the manifestation of response to adverse experiences (Blaze and Roth, 2013).

\section{Epigenetic Consequences of Childhood Adversity in Humans}

The challenge of translating these laboratory findings to research in humans stems primarily from the inability to study epigenetic variation in the brain of living individuals. However, in the case of childhood abuse, several studies have examined the epigenetic variation present in the postmortem brain tissue. Analyses of brain tissue from suicide victims with or without a history of childhood abuse and from non-suicide control subjects indicate that the expression of hippocampal GR is reduced in abused individuals and this reduction in transcriptional activity is associated with increased DNA methylation and reduced transcription factor binding within the NR3C1 gene promoter (McGowan et al, 2009). Thus, there appears to be translational relevance of the studies conducted in laboratory rodents. Genome-wide DNA methylation assays reveal that these effects are not specific to the NR3C1 gene promoter and include both hypomethylation and hypermethylation at hundreds of gene promoters within the hippocampus (Labonte et al, 2012). However, reliance on postmortem tissue, particularly from suicide victims, is a significant obstacle in expanding the study of epigenetic variation in humans and this has led to increasing reliance on peripheral DNA samples (ie, from blood or saliva). Although epigenetic profiles differentiate cell types, it may be the case that these peripheral sources of DNA can be used as a biomarker of early-life adversity (Uher and Weaver, 2014). Analyses of the NR3C1 gene promoter using blood samples indicate that childhood maltreatment (eg, physical, sexual, or emotional abuse) predicts elevated NR3C1 DNA methylation (Perroud et al, 2014). Moreover, childhood adversity-associated increases in NR3C1 DNA methylation predicts stress reactivity, which may have consequences for risk of psychopathology (Tyrka et al, 2012). Similar to findings in rodent models, human epigenetic variation in response to childhood adversity extends beyond NR3C1. Among orphanage-reared children, there is genome-wide hypermethylation detected in blood cells (Naumova et al, 2012). Broad epigenetic variation, including both DNA hypomethylation and DNA hypermethylation, is apparent in adult blood samples associated with childhood abuse (Suderman et al, 2014). Interestingly, gene targets identified in these analyses included several miRNAs, thus creating the potential for extensive epigenetic dysregulation downstream of the changes in DNA methylation. Thus, there are epigenetic signatures of early-life social adversity within peripheral tissues. There are also peripheral epigenetic markers of psychiatric disorder (D'Addario et al, 2012; Fuchikami et al, 2011). A recent study has demonstrated that some inter-individual variation in DNA methylation is correlated across brain and blood in humans (Davies et al, 2012), further suggesting that epigenetic profiling of peripheral tissues may be useful for studies of brain disorders. An important question to be addressed is the predictive value of adversity-induced epigenetic variation in blood or saliva for these neurodevelopmental and psychiatric outcomes.

\section{FROM ONE GENERATION TO THE NEXT}

There is increasing evidence for the impact of early-life adversity on offspring and grand-offspring (Champagne, 2008; Curley et al, 2011), yet the question remains as to how this is achieved. Here we will briefly consider two routes through which these effects could be achieved and how epigenetic variation induced by the quality of the postnatal environment may contribute to this transmission.

\section{Experience-Dependent Epigenetic Transmission}

The neural systems that regulate parental behavior are sensitive to the quality of caregiving experienced in infancy (Champagne, 2008). In rats, the experience of low levels of maternal care shifts the development of hypothalamic oxytocin and ER systems, rendering offspring less sensitive to hormonal priming, thus reducing maternal LG (see Figure 5). These neuroendocrine consequences of maternal care lead to the transmission of LG from one generation to the next (Champagne, 2008). With the transmission of maternal LG, there is also a multigenerational transmission of outcomes associated with the experience of low levels of LG, such as reduced neuronal plasticity and heightened HPA response to stress (Francis et al, 1999). Abusive caregiving may also alter the development of the maternal brain of offspring, leading to increased abusive care among abused offspring (Roth et al, 2009). In biparental species, fathers may similarly alter the neuroendocrine circuits regulating paternal behavior in male offspring leading to a transmission of variation in paternal behavior across generations (Bester-Meredith and Marler, 2003). These 


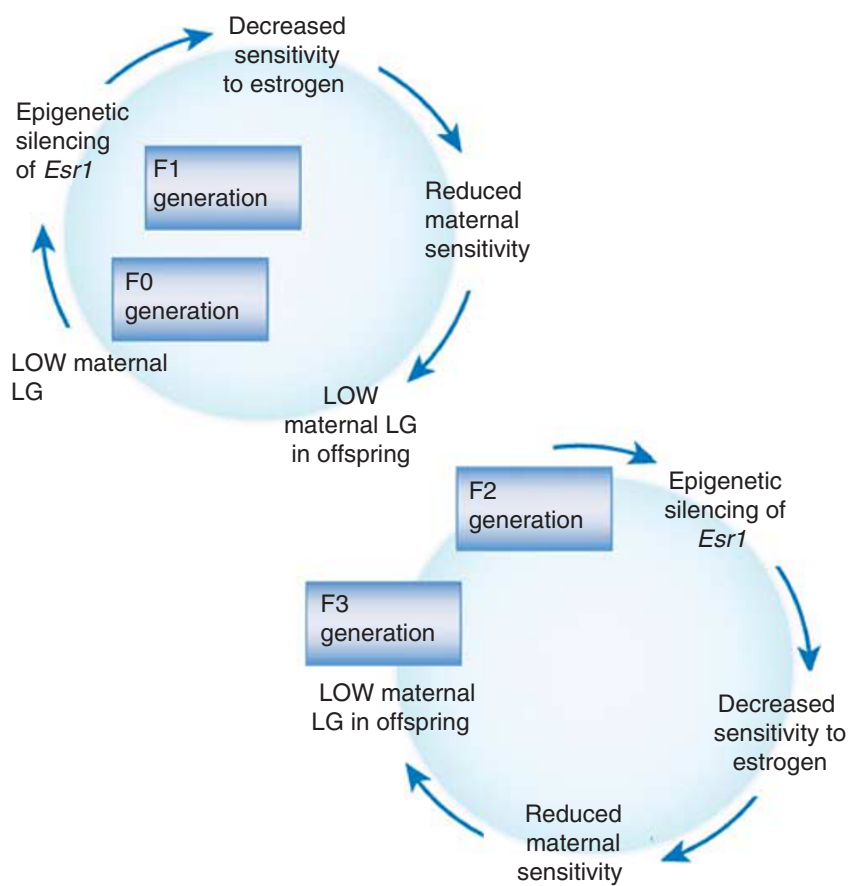

Figure 5. Cycle of epigenetic, neuroendocrine, and behavioral changes induced by low levels of maternal LG. Epigenetic regulation of Esr1 by maternal care can lead to a cascade of changes that alter F1 (offspring) and F2 (grand-offspring) development with the potential for the continuity of variation in maternal behavior to F3 generation offspring.

developmental effects of parent-offspring interactions may account for the intergenerational transmission of a broad range of behavioral phenotypes. The maintenance of these developmental effects into adulthood through epigenetic changes shapes the context of development for the next generation of offspring. Unlike a genetic route of inheritance, this transmission of behavior is highly plastic in response to environments experienced in later life (ie, stress, social isolation, and social interactions), such that when the environment changes, so too can the quality of parent-offspring interactions (Champagne and Meaney, 2006a; Champagne et al, 2007).

\section{Germline Epigenetic Inheritance}

There is increasing speculation that epigenetic modifications, which are heritable during mitosis, may also be inherited by subsequent generations (Daxinger and Whitelaw, 2012). Although there is genome-wide epigenetic re-programming during the post-fertilization phases of development, the observation of a transgenerational impact of parental experience that can persist even to F3 generation offspring has raised the issue of whether environmentally induced epigenetic changes are not completely erased and are transmitted via the germline. Evidence supporting these transgenerational effects has typically focused on the transmission of paternal epigenetic information (Anway and Skinner, 2006; Morgan and Bale, 2011; Saavedra-Rodriguez and Feig, 2013). In male mice, the experience of maternal separation during postnatal development is associated with impaired social behavior and altered anxiety- and depressive-like responses that persist across generations and coincide with altered serotonergic function (Franklin et al, 2010, 2011). Within the sperm of these males, postnatal maternal separation induces increased DNA methylation in $M e c p 2$ and the cannabinoid receptor type $1(\mathrm{Cb} 1)$ gene and decreased DNA methylation in the corticotropin releasing factor receptor 2 (Crfr2) gene (Franklin et al, 2010). These epigenetic changes also persist in the cortex and sperm of the offspring of these males. miRNAs may also serve a critical role in the transmission of the effects of maternal separation (Gapp et al, 2014). These findings complement increasing evidence that a broad range of exposures (ie, toxins, nutrition, and stress) can have germline epigenetic consequences (Curley et al, 2011).

A key question of relevance to both experience-dependent epigenetic transmission and germline epigenetic inheritance is regarding how the epigenetic marks are acquired. In the case of changes in hippocampal Nr3c1 DNA methylation, in vitro and in vivo studies suggest that neuronal activation, involving serotonergic and thyroid hormone signaling, may be precursors of the cellular and molecular changes that result in $\mathrm{Nr} 3 \mathrm{cl}$ hypermethylation as a consequence of the experience of low levels of maternal care (Champagne, 2013). However, reduced maternal care, maternal deprivation, and abuse have been observed to exert genome-wide epigenetic consequences (Labonte et al, 2012; Naumova et al, 2012; Provencal et al, 2012; Weaver et al, 2006) present in both the brain and in the periphery. In addition, although many studies have focused on epigenetic variation within the hippocampus, it is clear that multiple brain regions are sensitive to early-life experience-induced epigenetic disruption (ie, hypothalamus, prefrontal cortex, and amygdala; see Table 1). Thus, understanding the process of biological embedding of early-life experiences will require more comprehensive analyses of the cascade of molecular changes in multiple target tissues that occur subsequent to that experience. In light of the biphasic epigenetic changes observed within the brain in response to maternal separation (Suri et al, 2013), repeated measures over time will be essential to this understanding. Finally, understanding mechanisms through which heritable epigenetic variation is induced will require careful consideration of the crosstalk between the brain, endocrine system, and immune responses that may coordinate cellular and molecular responses across tissues (ie, neuronal and gametes).

\section{IMPLICATIONS AND FUTURE DIRECTIONS}

In the past decade, significant advances in our understanding of the role of epigenetic pathways in linking earlylife experiences to neurodevelopmental outcomes have emerged and it is increasingly evident that these epigenetic changes may underlie later-life risk of psychopathology. 
However, this approach to the origins of psychiatric dysfunction is still in its infancy, and there are yet many unanswered questions. Although the phenomenon whereby variation in childhood experiences is associated with epigenetic variation continues to be established and refined, as yet we have limited understanding of the process through which these epigenetic effects are achieved. Understanding the mechanisms inducing these effects will require the integration of high resolution and sensitive measures of multiple layers of epigenetic information (ie, DNA methylation, histone modifications, and miRNA). Of particular importance, when considering the application of epigenetics to the study of human neurodevelopment, will be the study of the interaction between DNA sequence variation and environmentally induced epigenetic variation. The reliance on peripheral measures of epigenetic variation will also require further validation to address key questions in the field: What is the meaning of these biomarkers for psychiatric dysfunction? How predictive are these peripheral epigenetic modifications of similar epigenetic profiles in the brain? Attaining answers to these questions and establishing the causal role of epigenetic variation in the development of later-life disease risk will pose significant challenges to the field, but have the potential to identify novel therapeutic targets and strategies.

In concert with these empirical questions, future research on the developmental impact of childhood experiences will require a theoretical framework that accounts for the broader evolutionary question of why these epigenetic pathways are engaged. Plasticity of the developing individual in response to the environment represents an adaptive system that better prepares the individual for living and reproducing in that environment. Deprivation of nurturing parental care can be viewed as a signal regarding environmental quality and responsiveness to that signal can be considered an important evolutionary advantage. In the case of the experience of low levels of LG, offspring are observed to adopt cognitive and reproductive strategies that may be better suited to a high threat environment (Cameron et al, 2005; Champagne et al, 2008). Interestingly, many of the animal models used in the study of parental care effects on offspring manipulate resource availability (ie, through reduced bedding material or variable foraging demand) creating strong parallels the impoverished socioeconomic environments in which human parent-offspring interactions are disrupted. The molecular and neurobiological adaptations to these environments may appear as dysfunction out of context and there is increasing suggestion that it is the mismatch between early-life compared with later-life environmental quality that drives the emergence of neurobiological disorder (Schmidt, 2011). Thus, the stability of environmental quality, such that early-life environments are similar to those that will be experienced in later life may be an important consideration within these developmental studies. This stability and predictability of environmental quality is critical to consider when the effects of parental care are transmitted across generations. Although transge- nerational effects of early-life experience may adapt offspring and their progeny, the benefit of this adaptation will be dependent on how well the environments of ancestors predict the environments of descendants. Within species with short lifespans and early emergence of reproduction (ie, laboratory rodents), there may be value to this epigenetic transmission. However, controversy regarding the applicability of these effects to humans will remain until we attain a deeper understanding of the mechanisms of environmentally induced epigenetic variation, the degree of plasticity/reversibility of these molecular changes, and the trade-offs that occur to maintain this dynamic route of inheritance.

\section{FUNDING AND DISCLOSURE}

The authors declare no conflict of interest.

\section{ACKNOWLEDGEMENTS}

This research is supported by NIMH funding 1P50MH090964-01A1.

\section{REFERENCES}

Adegbola A, Gao H, Sommer S, Browning M (2008). A novel mutation in JARID1C/ SMCX in a patient with autism spectrum disorder (ASD). Am J Med Genet $A$ 146A: 505-511.

Ader R (1970). The effects of early experience on the adrenocortical response to different magnitudes of stimulation. Physiol Behav 5: 837-839.

Andersen SL, Lyss PJ, Dumont NL, Teicher MH (1999). Enduring neurochemical effects of early maternal separation on limbic structures. Ann N Y Acad Sci 877 756-759.

Anway MD, Skinner MK (2006). Epigenetic transgenerational actions of endocrine disruptors. Endocrinology 147: S43-S49.

Bagot RC, van Hasselt FN, Champagne DL, Meaney MJ, Krugers HJ, Joels M (2009). Maternal care determines rapid effects of stress mediators on synaptic plasticity in adult rat hippocampal dentate gyrus. Neurobiol Learn Mem 92: 292-300.

Bagot RC, Zhang TY, Wen X, Nguyen TT, Nguyen HB, Diorio J et al. (2012). Variations in postnatal maternal care and the epigenetic regulation of metabotropic glutamate receptor 1 expression and hippocampal function in the rat. Proc Natl Acad Sci USA 109(Suppl 2): 17200-17207.

Baram TZ, Davis EP, Obenaus A, Sandman CA, Small SL, Solodkin A et al. (2012). Fragmentation and unpredictability of early-life experience in mental disorders. Am J Psychiatry 169: 907-915.

Barres R, Yan J, Egan B, Treebak JT, Rasmussen M, Fritz T et al. (2012). Acute exercise remodels promoter methylation in human skeletal muscle. Cell Metab 15: 405-411.

Barski A, Cuddapah S, Cui K, Roh TY, Schones DE, Wang Z et al. (2007). High-resolution profiling of histone methylations in the human genome. Cell 129 : 823-837.

Bernard K, Dozier M (2010). Examining infants' cortisol responses to laboratory tasks among children varying in attachment disorganization: stress reactivity or return to baseline? Dev Psychol 46: 1771-1778.

Bernstein E, Kim SY, Carmell MA, Murchison EP, Alcorn H, Li MZ et al. (2003). Dicer is essential for mouse development. Nat Genet 35: 215-217.

Bester-Meredith JK, Marler CA (2003). Vasopressin and the transmission of paternal behavior across generations in mated, cross-fostered Peromyscus mice. Behav Neurosci 117: 455-463.

Birnie AK, Taylor JH, Cavanaugh J, French JA (2013). Quality of maternal and paternal care predicts later stress reactivity in the cooperatively-breeding marmoset (Callithrix geoffroyi). Psychoneuroendocrinology 38: 3003-3014.

Blaze J, Roth TL (2013). Exposure to caregiver maltreatment alters expression levels of epigenetic regulators in the medial prefrontal cortex. Int J Dev Neurosci 31: $804-810$ 
Branchi I, Curley JP, D'Andrea I, Cirulli F, Champagne FA, Alleva E (2013). Early interactions with mother and peers independently build adult social skills and shape BDNF and oxytocin receptor brain levels. Psychoneuroendocrinology 38: 522-532.

Branchi I, D’Andrea I, Fiore M, Di Fausto V, Aloe L, Alleva E (2006a). Early social enrichment shapes social behavior and nerve growth factor and brain-derived neurotrophic factor levels in the adult mouse brain. Biol Psychiatry 60: 690-696.

Branchi I, D’Andrea I, Sietzema J, Fiore M, Di Fausto V, Aloe L et al. (2006b). Early social enrichment augments adult hippocampal BDNF levels and survival of BrdU-positive cells while increasing anxiety- and 'depression'-like behavior. J Neurosci Res 83: 965-973.

Branchi I, Karpova NN, D'Andrea I, Castren E, Alleva E (2011). Epigenetic modifications induced by early enrichment are associated with changes in timing of induction of BDNF expression. Neurosci Lett 495: 168-172.

Braun K, Seidel K, Holetschka R, Groeger N, Poeggel G (2013). Paternal deprivation alters the development of catecholaminergic innervation in the prefrontal cortex and related limbic brain regions. Brain Struct Funct 218: 859-872.

Bredy TW, Brown RE, Meaney MJ (2007). Effect of resource availability on biparental care, and offspring neural and behavioral development in the California mouse (Peromyscus californicus). Eur J Neurosci 25: 567-575.

Cameron N, Del Corpo A, Diorio J, McAllister K, Sharma S, Meaney MJ (2008). Maternal programming of sexual behavior and hypothalamic-pituitary-gonadal function in the female rat. PLoS One 3: e2210.

Cameron NM, Champagne FA, Parent C, Fish EW, Ozaki-Kuroda K, Meaney MJ (2005). The programming of individual differences in defensive responses and reproductive strategies in the rat through variations in maternal care. Neurosci Biobehav Rev 29: 843-865.

Cao Y, Wu R, Tai F, Zhang X, Yu P, An X et al. (2014). Neonatal paternal deprivation impairs social recognition and alters levels of oxytocin and estrogen receptor alpha mRNA expression in the MeA and NAcc, and serum oxytocin in mandarin voles. Horm Behav 65: 57-65.

Carlson EA (1998). A prospective longitudinal study of attachment disorganization/ disorientation. Child Dev 69: 1107-1128.

Carlson EA, Egeland B, Sroufe LA (2009). A prospective investigation of the development of borderline personality symptoms. Dev Psychopathol 21: 1311-1334.

Carpenter LL, Shattuck TT, Tyrka AR, Geracioti TD, Price LH (2011). Effect of childhood physical abuse on cortisol stress response. Psychopharmacology (Berl) 214: 367-375

Caspi A, Sugden K, Moffitt TE, Taylor A, Craig IW, Harrington H et al. (2003). Influence of life stress on depression: moderation by a polymorphism in the 5-HTT gene. Science 301: 386-389.

Champagne DL, Bagot RC, van Hasselt F, Ramakers G, Meaney MJ, de Kloet ER et al. (2008). Maternal care and hippocampal plasticity: evidence for experiencedependent structural plasticity, altered synaptic functioning, and differential responsiveness to glucocorticoids and stress. J Neurosci 28: 6037-6045.

Champagne F, Diorio J, Sharma S, Meaney MJ (2001). Naturally occurring variations in maternal behavior in the rat are associated with differences in estrogen-inducible central oxytocin receptors. Proc Natl Acad Sci USA 98: 12736-12741.

Champagne FA (2008). Epigenetic mechanisms and the transgenerational effects of maternal care. Front Neuroendocrinol 29: 386-397.

Champagne FA (2013). Early environments, glucocorticoid receptors, and behavioral epigenetics. Behav Neurosci 127: 628-636.

Champagne FA, Francis DD, Mar A, Meaney MJ (2003a). Variations in maternal care in the rat as a mediating influence for the effects of environment on development. Physiol Behav 79: 359-371.

Champagne FA, Meaney MJ (2006a). Stress during gestation alters postpartum maternal care and the development of the offspring in a rodent model. Biol Psychiatry 59: 1227-1235.

Champagne FA, Meaney MJ (2007). Transgenerational effects of social environment on variations in maternal care and behavioral response to novelty. Behav Neurosci 121: 1353-1363

Champagne FA, Weaver IC, Diorio J, Dymov S, Szyf M, Meaney MJ (2006b). Maternal care associated with methylation of the estrogen receptor-alpha1b promoter and estrogen receptor-alpha expression in the medial preoptic area of female offspring. Endocrinology 147: 2909-2915.

Champagne FA, Weaver IC, Diorio J, Sharma S, Meaney MJ (2003b). Natural variations in maternal care are associated with estrogen receptor alpha expression and estrogen sensitivity in the medial preoptic area. Endocrinology 144: 4720-4724.

Chatterjee D, Chatterjee-Chakraborty M, Rees S, Cauchi J, de Medeiros CB, Fleming AS (2007). Maternal isolation alters the expression of neural proteins during development: 'stroking' stimulation reverses these effects. Brain Res 1158: 11-27.
Coplan JD, Altemus M, Mathew SJ, Smith EL, Sharf B, Coplan PM et al. (2005). Synchronized maternal-infant elevations of primate CSF CRF concentrations in response to variable foraging demand. CNS Spectr 10: 530-536.

Coplan JD, Smith EL, Altemus M, Mathew SJ, Perera T, Kral JG et al. (2006). Maternal-infant response to variable foraging demand in nonhuman primates: effects of timing of stressor on cerebrospinal fluid corticotropin-releasing factor and circulating glucocorticoid concentrations. Ann N Y Acad Sci 1071: 525-533.

Curley JP, Davidson S, Bateson P, Champagne FA (2009). Social enrichment during postnatal development induces transgenerational effects on emotional and reproductive behavior in mice. Front Behav Neurosci 3: 25.

Curley JP, Mashoodh R, Champagne FA (2011). Epigenetics and the origins of paternal effects. Horm Behav 59: 306-314.

D'Addario C, Dell'Osso B, Palazzo MC, Benatti B, Lietti L, Cattaneo E et al. (2012). Selective DNA methylation of BDNF promoter in bipolar disorder: differences among patients with BDI and BDII. Neuropsychopharmacology 37: 1647-1655.

Davies MN, Volta M, Pidsley R, Lunnon K, Dixit A, Lovestone S et al. (2012). Functional annotation of the human brain methylome identifies tissue-specific epigenetic variation across brain and blood. Genome Biol 13: R43.

Davis TH, Cuellar TL, Koch SM, Barker AJ, Harfe BD, McManus MT et al. (2008). Conditional loss of Dicer disrupts cellular and tissue morphogenesis in the cortex and hippocampus. J Neurosci 28: 4322-4330.

Daxinger L, Whitelaw E (2012). Understanding transgenerational epigenetic inheritance via the gametes in mammals. Nat Rev Genet 13: 153-162.

Day JJ, Sweatt JD (2010). DNA methylation and memory formation. Nat Neurosci 13: 1319-1323.

De Bellis MD (2005). The psychobiology of neglect. Child Maltreat 10: 150-172.

De Wolff MS, van ljzendoorn MH (1997). Sensitivity and attachment: a metaanalysis on parental antecedents of infant attachment. Child Dev 68: 571-591.

Dettmer AM, Novak MA, Suomi SJ, Meyer JS (2012). Physiological and behavioral adaptation to relocation stress in differentially reared rhesus monkeys: hair cortisol as a biomarker for anxiety-related responses. Psychoneuroendocrinology 37: 191-199.

El-Maarri O, Kareta MS, Mikeska T, Becker T, Diaz-Lacava A, Junen J et al. (2009). A systematic search for DNA methyltransferase polymorphisms reveals a rare DNMT3L variant associated with subtelomeric hypomethylation. Hum Mol Genet 18: $1755-1768$.

Engert V, Efanov SI, Dedovic K, Duchesne A, Dagher A, Pruessner JC (2010). Perceived early-life maternal care and the cortisol response to repeated psychosocial stress. J Psychiatry Neurosci 35: 370-377.

Fairbanks LA, McGuire MT (1988). Long-term effects of early mothering behavior on responsiveness to the environment in vervet monkeys. Dev Psychobiol 21: 711-724.

Fan G, Hutnick L (2005). Methyl-CpG binding proteins in the nervous system. Cell Res 15: 255-261.

Francis D, Diorio J, Liu D, Meaney MJ (1999). Nongenomic transmission across generations of maternal behavior and stress responses in the rat. Science $\mathbf{2 8 6}$ : 1155-1158.

Franklin TB, Linder N, Russig H, Thony B, Mansuy IM (2011). Influence of early stress on social abilities and serotonergic functions across generations in mice. PLoS One 6: e21842.

Franklin TB, Russig H, Weiss IC, Graff J, Linder N, Michalon A et al. (2010). Epigenetic transmission of the impact of early stress across generations. Biol Psychiatry 68: 408-415.

Frazier CR, Trainor BC, Cravens CJ, Whitney TK, Marler CA (2006). Paternal behavior influences development of aggression and vasopressin expression in male California mouse offspring. Horm Behav 50: 699-707.

Fuchikami M, Morinobu S, Segawa M, Okamoto Y, Yamawaki S, Ozaki N et al. (2011). DNA methylation profiles of the brain-derived neurotrophic factor (BDNF) gene as a potent diagnostic biomarker in major depression. PLoS One 6: e23881.

Gapp K, Jawaid A, Sarkies P, Bohacek J, Pelczar P, Prados J et al. (2014). Implication of sperm RNAs in transgenerational inheritance of the effects of early trauma in mice. Nat Neurosci 17: 667-669.

Gleason ED, Marler CA (2013). Non-genomic transmission of paternal behaviour between fathers and sons in the monogamous and biparental California mouse. Proc Biol Sci 280: 20130824.

Gorman JM, Mathew S, Coplan J (2002). Neurobiology of early life stress: nonhuman primate models. Semin Clin Neuropsychiatry 7: 96-103.

Gunnar MR, Morison SJ, Chisholm K, Schuder M (2001). Salivary cortisol levels in children adopted from romanian orphanages. Dev Psychopathol 13: 611-628.

Hane AA, Fox NA (2006). Ordinary variations in maternal caregiving influence human infants' stress reactivity. Psychol Sci 17: 550-556.

Hane AA, Henderson HA, Reeb-Sutherland BC, Fox NA (2010). Ordinary variations in human maternal caregiving in infancy and biobehavioral development in early childhood: A follow-up study. Dev Psychobiol 52: 558-567. 
Harlow HF, Dodsworth RO, Harlow MK (1965). Total social isolation in monkeys. Proc Natl Acad Sci USA 54: 90-97.

Heim C, Shugart M, Craighead WE, Nemeroff CB (2010). Neurobiological and psychiatric consequences of child abuse and neglect. Dev Psychobiol 52: 671-690.

Hostinar CE, Stellern SA, Schaefer C, Carlson SM, Gunnar MR (2012). Associations between early life adversity and executive function in children adopted internationally from orphanages. Proc Natl Acad Sci USA 109(Suppl 2): 17208-17212.

Howell BR, McCormack KM, Grand AP, Sawyer NT, Zhang X, Maestripieri D et al. (2013). Brain white matter microstructure alterations in adolescent rhesus monkeys exposed to early life stress: associations with high cortisol during infancy. Biol Mood Anxiety Disord 3: 21.

Jackowski A, Perera TD, Abdallah CG, Garrido G, Tang CY, Martinez J et al. (2011). Early-life stress, corpus callosum development, hippocampal volumetrics, and anxious behavior in male nonhuman primates. Psychiatry Res 192: 37-44.

Jackson-Grusby L, Beard C, Possemato R, Tudor M, Fambrough D, Csankovszki G et al. (2001). Loss of genomic methylation causes p53-dependent apoptosis and epigenetic deregulation. Nat Genet 27: 31-39.

Jenuwein T, Allis CD (2001). Translating the histone code. Science 293: 1074-1080.

Jia R, Tai F, An S, Zhang X, Broders H (2009). Effects of neonatal paterna deprivation or early deprivation on anxiety and social behaviors of the adults in mandarin voles. Behav Processes 82: 271-278.

Johnson JG, Cohen P, Brown J, Smailes EM, Bernstein DP (1999). Childhood maltreatment increases risk for personality disorders during early adulthood. Arch Gen Psychiatry 56: 600-606.

Kember RL, Dempster EL, Lee TH, Schalkwyk LC, Mill J, Fernandes C (2012). Maternal separation is associated with strain-specific responses to stress and epigenetic alterations to Nr3c1, Avp, and Nr4a1 in mouse. Brain Behav 2 . 455-467.

Kinnally EL, Capitanio JP, Leibel R, Deng L, LeDuc C, Haghighi F et al. (2010). Epigenetic regulation of serotonin transporter expression and behavior in infant rhesus macaques. Genes, Brain and Behavior 9: 575-582.

Koch CM, Andrews RM, Flicek P, Dillon SC, Karaoz U, Clelland GK et al. (2007). The landscape of histone modifications across $1 \%$ of the human genome in five human cell lines. Genome Res 17: 691-707.

Koch H, McCormack K, Sanchez MM, Maestripieri D (2014). The development of the hypothalamic-pituitary-adrenal axis in rhesus monkeys: Effects of age, sex, and early experience. Dev Psychobiol 56: 86-95.

Kundakovic M, Lim S, Gudsnuk K, Champagne FA (2013). Sex-specific and straindependent effects of early life adversity on behavioral and epigenetic outcomes. Front Psychiatry 4: 78.

Kurian JR, Olesen KM, Auger AP (2010). Sex differences in epigenetic regulation of the estrogen receptor-alpha promoter within the developing preoptic area Endocrinology 151: 2297-2305.

Labonte B, Suderman M, Maussion G, Navaro L, Yerko V, Mahar I et al. (2012). Genome-wide epigenetic regulation by early-life trauma. Arch Gen Psychiatry 69: 722-731.

Lee MHS, Williams DI (1974). Changes in licking behaviour of rat mother following handling of young. Anim Behav 22: 679-681.

Lehmann J, Pryce CR, Bettschen D, Feldon J (1999). The maternal separation paradigm and adult emotionality and cognition in male and female Wistar rats. Pharmacol Biochem Behav 64: 705-715.

Levy F, Melo Al, Galef BG Jr., Madden M, Fleming AS (2003). Complete maternal deprivation affects social, but not spatial, learning in adult rats. Dev Psychobiol 43: 177-191.

Liu D, Diorio J, Day JC, Francis DD, Meaney MJ (2000). Maternal care, hippocampal synaptogenesis and cognitive development in rats. Nat NeurosCi 3: 799-806.

Liu D, Diorio J, Tannenbaum B, Caldji C, Francis D, Freedman A et al. (1997). Maternal care, hippocampal glucocorticoid receptors, and hypothalamicpituitary-adrenal responses to stress. Science 277: 1659-1662.

Lovic V, Fleming AS (2004). Artificially-reared female rats show reduced prepulse inhibition and deficits in the attentional set shifting task-reversal of effects with maternal-like licking stimulation. Behav Brain Res 148: 209-219.

Lovic V, Keen D, Fletcher PJ, Fleming AS (2011). Early-life maternal separation and social isolation produce an increase in impulsive action but not impulsive choice. Behav Neurosci 125: 481-491.

Maestripieri D, Higley JD, Lindell SG, Newman TK, McCormack KM, Sanchez MM (2006). Early maternal rejection affects the development of monoaminergic systems and adult abusive parenting in rhesus macaques (Macaca mulatta) Behav Neurosci 120: 1017-1024

Maheu FS, Dozier M, Guyer AE, Mandell D, Peloso E, Poeth K et al. (2010). A preliminary study of medial temporal lobe function in youths with a history of caregiver deprivation and emotional neglect. Cogn Affect Behav Neurosci 10 34-49.
McCormack K, Sanchez MM, Bardi M, Maestripieri D (2006). Maternal care patterns and behavioral development of rhesus macaque abused infants in the first 6 months of life. Dev Psychobiol 48: 537-550.

McGoron L, Gleason MM, Smyke AT, Drury SS, Nelson CA 3rd, Gregas MC et al. (2012). Recovering from early deprivation: attachment mediates effects of caregiving on psychopathology. J Am Acad Child Adolesc Psychiatry 51: 683-693.

McGowan PO, Sasaki A, D’Alessio AC, Dymov S, Labonte B, Szyf M et al. (2009). Epigenetic regulation of the glucocorticoid receptor in human brain associates with childhood abuse. Nat Neurosci 12: 342-348.

McGowan PO, Suderman M, Sasaki A, Huang TC, Hallett M, Meaney MJ et al. (2011). Broad epigenetic signature of maternal care in the brain of adult rats. PLoS One 6: e14739.

Meaney MJ, Aitken DH, Bodnoff SR, Iny LJ, Tatarewicz JE, Sapolsky RM (1985). Early postnatal handling alters glucocorticoid receptor concentrations in selected brain regions. Behav Neurosci 99: 765-770.

Morgan CP, Bale TL (2011). Early prenatal stress epigenetically programs dysmasculinization in second-generation offspring via the paternal lineage. J Neurosci 31: 11748-11755.

Murgatroyd C, Patchev AV, Wu Y, Micale V, Bockmuhl Y, Fischer D et al. (2009). Dynamic DNA methylation programs persistent adverse effects of early-life stress. Nat Neurosci 12: 1559-1566.

Narita K, Fujihara K, Takei Y, Suda M, Aoyama Y, Uehara T et al. (2012). Associations among parenting experiences during childhood and adolescence, hypothalamus-pituitary-adrenal axis hypoactivity, and hippocampal gray matter volume reduction in young adults. Hum Brain Mapp 33: 2211-2223.

Narita K, Takei Y, Suda M, Aoyama Y, Uehara T, Kosaka H et al. (2010). Relationship of parental bonding styles with gray matter volume of dorsolateral prefrontal cortex in young adults. Prog Neuropsychopharmacol Biol Psychiatry.

Naumova OY, Lee M, Koposov R, Szyf M, Dozier M, Grigorenko EL (2012). Differential patterns of whole-genome DNA methylation in institutionalized children and children raised by their biological parents. Dev Psychopathol 24 143-155

O'Connor TG, Rutter M, Beckett C, Keaveney L, Kreppner JM (2000). The effects of global severe privation on cognitive competence: extension and longitudinal follow-up. English and Romanian Adoptees Study Team. Child Dev 71: 376-390.

Okano M, Bell DW, Haber DA, Li E (1999). DNA methyltransferases Dnmt3a and Dnmt3b are essential for de novo methylation and mammalian development. Cell 99: 247-257.

Parker G (1990). The parental bonding instrument: a decade of research. Soc Psychiatry Psychiatr Epidemiol 25: 281-282.

Pauli A, Rinn JL, Schier AF (2011). Non-coding RNAs as regulators of embryogenesis. Nat Rev Genet 12: 136-149.

Pena CJ, Neugut YD, Champagne FA (2013). Developmental timing of the effects of maternal care on gene expression and epigenetic regulation of hormone receptor levels in female rats. Endocrinology 154: 4340-4351.

Perroud N, Dayer A, Piguet C, Nallet A, Favre S, Malafosse A et al. (2014). Childhood maltreatment and methylation of the glucocorticoid receptor gene NR3C1 in bipolar disorder. Br J Psychiatry 204: 30-35.

Peterson CL, Laniel MA (2004). Histones and histone modifications. Curr Biol 14 R546-R551.

Pinkernelle J, Abraham A, Seidel K, Braun K (2009). Paternal deprivation induces dendritic and synaptic changes and hemispheric asymmetry of pyramidal neurons in the somatosensory cortex. Dev Neurobio/ 69: 663-673.

Provencal N, Suderman MJ, Guillemin C, Massart R, Ruggiero A, Wang D et al. (2012). The signature of maternal rearing in the methylome in rhesus macaque prefrontal cortex and T cells. J Neurosci 32: 15626-15642.

Pruessner JC, Champagne F, Meaney MJ, Dagher A (2004). Dopamine release in response to a psychological stress in humans and its relationship to early life maternal care: a positron emission tomography study using [11C]raclopride. J Neurosci 24: 2825-2831.

Razin A (1998). CpG methylation, chromatin structure and gene silencing-a threeway connection. EMBO J 17: 4905-4908.

Rice CJ, Sandman CA, Lenjavi MR, Baram TZ (2008). A novel mouse model for acute and long-lasting consequences of early life stress. Endocrinology 149 $4892-4900$

Rodenas-Ruano A, Chavez AE, Cossio MJ, Castillo PE, Zukin RS (2012). RESTdependent epigenetic remodeling promotes the developmental switch in synaptic NMDA receptors. Nat Neurosci 15: 1382-1390.

Roth TL, Lubin FD, Funk AJ, Sweatt JD (2009). Lasting epigenetic influence of early-life adversity on the BDNF gene. Biol Psychiatry 65: 760-769.

Rutter M, O'Connor TG (2004). Are there biological programming effects for psychological development? Findings from a study of Romanian adoptees. Dev Psychol 40: 81-94. 
Saavedra-Rodriguez L, Feig LA (2013). Chronic social instability induces anxiety and defective social interactions across generations. Biol Psychiatry 73: 44-53.

Sanchez MM, McCormack K, Grand AP, Fulks R, Graff A, Maestripieri D (2010). Effects of sex and early maternal abuse on adrenocorticotropin hormone and cortisol responses to the corticotropin-releasing hormone challenge during the first 3 years of life in group-living rhesus monkeys. Dev Psychopathol 22: 45-53.

Sapolsky RM, Meaney MJ, McEwen BS (1985). The development of the glucocorticoid receptor system in the rat limbic brain. III. Negative-feedback regulation. Brain Res 350: 169-173.

Sato F, Tsuchiya S, Meltzer SJ, Shimizu K (2011). MicroRNAs and epigenetics. FEBS J 278: 1598-1609.

Schmidt MV (2011). Animal models for depression and the mismatch hypothesis of disease. Psychoneuroendocrinology 36: 330-338.

Seidel K, Poeggel G, Holetschka R, Helmeke C, Braun K (2011). Paternal deprivation affects the development of corticotrophin-releasing factor-expressing neurones in prefrontal cortex, amygdala and hippocampus of the biparental Octodon degus. J Neuroendocrinol 23: 1166-1176.

Smyke AT, Dumitrescu A, Zeanah CH (2002). Attachment disturbances in young children. I: the continuum of caretaking casualty. J Am Acad Child Adolesc Psychiatry 41: 972-982.

Spinelli S, Chefer S, Carson RE, Jagoda E, Lang L, Heilig M et al. (2010). Effects of early-life stress on serotonin $(1 \mathrm{~A})$ receptors in juvenile Rhesus monkeys measured by positron emission tomography. Biol Psychiatry 67: 1146-1153.

Spinelli S, Chefer S, Suomi SJ, Higley JD, Barr CS, Stein E (2009). Early-life stress induces long-term morphologic changes in primate brain. Arch Gen Psychiatry 66: 658-665.

Sroufe LA (2005). Attachment and development: a prospective, longitudinal study from birth to adulthood. Attach Hum Dev 7: 349-367.

Stanton ME, Gutierrez YR, Levine S (1988). Maternal deprivation potentiates pituitary-adrenal stress responses in infant rats. Behav Neurosci 102: 692-700.

Suderman M, Borghol N, Pappas JJ, Pinto Pereira SM, Pembrey M, Hertzman C et al. (2014). Childhood abuse is associated with methylation of multiple loci in adult DNA. BMC Med Genomics 7: 13.

Suomi SJ (1991). Early stress and adult emotional reactivity in rhesus monkeys. Ciba Found Symp 156: 171-183.

Suomi SJ, Harlow HF, Kimball SD (1971). Behavioral effects of prolonged partial social isolation in the rhesus monkey. Psychol Rep 29: 1171-1177.

Suri D, Veenit V, Sarkar A, Thiagarajan D, Kumar A, Nestler EJ et al. (2013). Early stress evokes age-dependent biphasic changes in hippocampal neurogenesis, BDNF expression, and cognition. Biol Psychiatry 73: 658-666.

Tahiliani M, Mei P, Fang R, Leonor T, Rutenberg M, Shimizu F et al. (2007). The histone H3K4 demethylase SMCX links REST target genes to X-linked mental retardation. Nature 447: 601-605.

Tang AC (2001). Neonatal exposure to novel environment enhances hippocampaldependent memory function during infancy and adulthood. Learn Mem 8: 257-264.
Tang AC, Akers KG, Reeb BC, Romeo RD, McEwen BS (2006). Programming social, cognitive, and neuroendocrine development by early exposure to novelty. Proc Natl Acad Sci USA 103: 15716-15721.

Taylor SM, Jones PA (1985). Cellular differentiation. Int J Obes 9(Suppl 1): 15-21.

Toda H, Boku S, Nakagawa S, Inoue T, Kato A, Takamura N et al. (2014). Maternal separation enhances conditioned fear and decreases the mRNA levels of the neurotensin receptor 1 gene with hypermethylation of this gene in the rat amygdala. PLoS One 9: e97421.

Tottenham N, Hare TA, Millner A, Gilhooly T, Zevin JD, Casey BJ (2011). Elevated amygdala response to faces following early deprivation. Dev Sci 14: 190-204.

Trickett P, McBride-Chang C (1995). The developmental impact of different forms of child abuse and neglect. Devel Rev 15: 11-37.

Tyrka AR, Price LH, Marsit C, Walters OC, Carpenter LL (2012). Childhood adversity and epigenetic modulation of the leukocyte glucocorticoid receptor: preliminary findings in healthy adults. PLoS One 7: e30148.

Uher R, Weaver IC (2014). Epigenetic traces of childhood maltreatment in peripheral blood: a new strategy to explore gene-environment interactions. Br J Psychiatry 204: 3-5.

van Harmelen AL, van Tol MJ, van der Wee NJ, Veltman DJ, Aleman A, Spinhoven P et al. (2010). Reduced medial prefrontal cortex volume in adults reporting childhood emotional maltreatment. Biol Psychiatry 68: 832-838.

van ljzendoorn MH, Schuengel C, Bakermans-Kranenburg MJ (1999). Disorganized attachment in early childhood: meta-analysis of precursors, concomitants, and sequelae. Dev Psychopathol 11: 225-249.

Wang A, Nie W, Li H, Hou Y, Yu Z, Fan Q et al. (2014). Epigenetic upregulation of corticotrophin-releasing hormone mediates postnatal maternal separationinduced memory deficiency. PLoS One 9: e94394.

Wang J, Tai F, Yan X, Yu P (2012). Paternal deprivation alters play-fighting, serum corticosterone and the expression of hypothalamic vasopressin and oxytocin in juvenile male mandarin voles. J Comp Physiol A Neuroethol Sens Neural Behav Physiol 198: 787-796.

Wang XD, Rammes G, Kraev I, Wolf M, Liebl C, Scharf SH et al. (2011). Forebrain CRF(1) modulates early-life stress-programmed cognitive deficits. J Neurosci 31: 13625-13634

Weaver IC, Cervoni N, Champagne FA, D'Alessio AC, Sharma S, Seckl JR et al. (2004). Epigenetic programming by maternal behavior. Nat Neurosci 7: 847-854.

Weaver IC, Meaney MJ, Szyf M (2006). Maternal care effects on the hippocampal transcriptome and anxiety-mediated behaviors in the offspring that are reversible in adulthood. Proc Natl Acad Sci USA 103: 3480-3485.

Wu Y, Patchev AV, Daniel G, Almeida OF, Spengler D (2014). Early-life stress reduces DNA methylation of the pomc gene in male mice. Endocrinology 155: 1751-1762.

Yu P, An S, Tai F, Zhang X, He F, Wang J et al. (2012). The effects of neonatal paternal deprivation on pair bonding, NAcc dopamine receptor mRNA expression and serum corticosterone in mandarin voles. Horm Behav 61: 669-677.

Zhang TY, Hellstrom IC, Bagot RC, Wen X, Diorio J, Meaney MJ (2010). Maternal care and DNA methylation of a glutamic acid decarboxylase 1 promoter in rat hippocampus. J Neurosci 30: 13130-13137. 